\title{
Exercício do poder e manifestações da verdade na análise foucaultiana do Édipo Rei
}

\author{
Exercise of power and manifestations of truth in Foucault's analysis of \\ Oedipus Rei
}

\author{
IGOR CORRÊA DE BARROS ${ }^{1}$
}

\begin{abstract}
Resumo: Este artigo tem por objetivo apresentar Michel Foucault como um intérprete original e assíduo de Édipo Rei, retomando a leitura realizada pelo autor no curso Do governo dos vivos (1979-1980), à luz dos aportes teórico-metodológicos da ética. Pretendese discutir a tragédia de Sófocles em termos de aleturgia, como um ritual de manifestação de verdade e exercício de poder. Para isso, apresenta-se o conceito de aleturgia e rituais de verdade; em seguida caracterizam-se as formas de aleturgia encontradas em Édipo Rei; por fim, investiga-se em que consiste o saber de Édipo e a relação entre a arte de governar os homens e a autoaleturgia.
\end{abstract}

Palavras-chave: Foucault. Aleturgia. Poder.

Abstract: This article aims to present Michel Foucault as an original and assiduous interpreter of Oedipus Rex, resuming the author's rereading in On the Government of the Living's lectures (1979-1980), in the light of the theoretical-methodological contributions of ethics. It intends to discuss the Sophocles' tragedy in terms of aleturgy, as a ritual of manifestation of truth and exercise of power. It starts presenting the concept of aleturgy and rituals of truth; then it characterizes the aleturgy forms found in Oedipus Rex. Finally, it investigates in what consists the Oedipus' knowledge, and the relations between the art of governing men and self-aleturgy.

Keywords: Foucault. Aleturgy. Power.

\section{Considerações iniciais}

Michel Foucault é um dos mais potentes filósofos contemporâneos, que fez de sua obra instrumento de problematização das questões de seu tempo. Seus estudos perpassam pelos mais variados campos, desde a loucura, medicina, ciências humanas, sistema prisional, até as formas de governo. A obra de Foucault pode ser dividida em três "fases", três tipos de investigação histórica nas quais o autor se apoiou para guiar seu pensamento: arqueologia, marcada pelas obras As palavras $e$ as coisas (1966) e Arqueologia do saber (1969); genealogia, representada por Vigiar e Punir (1975) e A vontade de saber (1976); e ética ou estética da existência, presentes nos volumes 2 e 3 da História da Sexualidade: Os usos do prazer (1984) e O cuidado de si (1984).

\footnotetext{
${ }^{1}$ Graduando em Filosofia pela Universidade Federal de São João del Rei. Formado em Técnico em Informática pelo Instituto Federal de Educação, Ciência e Tecnologia do Sudeste de Minas Gerais, Campus Rio Pomba. E-mail: igorcorreadebarros@yahoo.com.br
} 
Na primeira fase, Foucault dedicou-se a analisar a produção e a validação dos regimes de verdades; sobretudo, as ciências e os discursos pelos quais os seres humanos investigam a si mesmos, como as ciências humanas e a psiquiatria. Rabinow e Dreyfus avaliam que "os primeiros trabalhos de Foucault estão centrados nas análises dos sistemas de instituições e práticas discursivas historicamente situadas" (DREYFUS; RABINOW, 1995, p.121). A questão dos enunciados prevalece na fase genealógica: a produção de verdades é situada como parte de um sistema complexo de exercício de poder, no qual mecanismos de poder articulam-se com os saberes para produzir verdade. Na última fase de sua vida, os regimes de verdade são situados como parte do campo das técnicas de si, no domínio da ética.

Ao longo de sua trajetória, Foucault recorreu ao menos seis vezes ao texto de Édipo Rei ${ }^{2}$, peça escrita por Sófocles. A história do herói trágico serviu de apoio para estudar não só a produção de verdades, mas também outros temas como as formas de governar, as relações entre poder e saber, o inquérito, a genealogia da sociedade punitiva e manifestação da verdade.

Em 1980, ao iniciar seus estudos no campo da ética, Foucault desloca sua atenção do conceito saber-poder para o conceito de governo, mais precisamente para a investigação do governo dos vivos pela verdade e recorre à peça para analisar as manifestações de verdade que acompanham o exercício do poder, que o autor chamou de aleturgia.

Foucault pode ser considerado um intérprete original da história de Édipo, e sua reflexão contribui tanto para o campo da literatura quanto para o campo da filosofia. Ao manter um diálogo vivo e intenso com outros estudiosos da peça, como Friedrich Nietzsche, Claude Lévi-Strauss, Jean-Pierre Vernant e Pierre Vidal-Naquet, Gilles Deleuze e Félix Guattari, o pensador francês atualizou as discussões em torno do texto e lançou um novo olhar sobre a história de Édipo, não mais do complexo de Édipo freudiano, como se a nossa civilização carregasse "a mesma maldição que o oráculo pronunciou contra ele” (Vernant e Pierre, 1999, p.54). Em uma conferência pronunciada em 1973, Foucault rompe com o complexo freudiano edipiano pai-mãefilho ao afirmar que, se há um complexo de Édipo em nossa sociedade, esse complexo:

[...] não diz respeito ao nosso inconsciente e ao nosso desejo, nem às relações entre desejo e inconsciente. Se existe complexo de Édipo, ele se dá não no nível individual, mas coletivo; não a propósito de desejo e inconsciente, mas de poder e de saber. (FOUCAULT, 2002, p. 31).

\footnotetext{
${ }^{2}$ Foucault havia analisado Édipo rei, pela primeira vez no curso $A$ vontade de saber (1971-1972). Em seguida retomou o texto em uma conferência pronunciada em 1972, O saber de Édipo. No ano seguinte promoveu uma releitura de Édipo na conferência $A$ verdade e as formas jurídicas, no Rio de Janeiro. Em 1980, no curso Do governo dos vivos, Foucault retoma o texto, dessa vez sobre a ótica dos atos de verdade (objeto desse artigo). Outras duas ocasiões marcaram a utilização de Édipo rei: Malfazer, dizer a verdade, em 1981 e no curso O governo de si e dos outros (1983-1984).
} 
Frente a esses aspectos, este artigo se compromete a apresentar leitura realizada por Foucault no curso Do governo dos vivos, em que o autor relaciona a peça com os atos de verdade, nos quais o indivíduo se compromete a dizer a verdade sobre as coisas (aleturgia) e sobre si mesmo (autoaleturgia). Focaremos na mudança teórica e nos estudos realizados em Do governo dos vivos, momento em que Foucault inicia seus estudos no campo da ética, realizando uma análise dos atos de verdade presentes no cristianismo primitivo, como o batismo, a penitência e a direção da consciência.

Na seção a seguir, apresentaremos a releitura aletúrgica que Foucault realiza da obra de Sófocles, na qual o filósofo faz uma relação entre o exercício do poder e a manifestação da verdade, apresentada na trama em duas formas de aleturgias: aleturgia dos deuses e aleturgia dos escravos. Em seguida, exploraremos Édipo como operador da verdade: a importância do "eu" nos procedimentos de veridicção; a relação entre arte de governar os homens e autoaleturgia; e em que consiste o poder de Édipo, aspecto central da peça.

\section{Aleturgia e os rituais de manifestação da verdade}

O curso Do governo dos vivos marca o início dos estudos de Foucault no campo da ética, tema que o autor perseguirá até o final de sua vida. O curso é uma continuação dos estudos feitos a propósito da noção de governo, temática iniciada em Segurança, território e população (1977-1978). O campo aberto pelo estudo do biopoder atribuiu novos contornos à analítica do poder: não mais o estudo dos poderes periféricos, sobretudo a disciplina, e sim dos fenômenos políticos de maior escala, que dizem respeito à regulação dos aspectos biológicos da população.

A noção de governo presente no título do curso de 1980 enfatiza a retomada do conceito, como forma de analisar os mecanismos pelos quais o poder se encarrega da vida humana enquanto população, de modo que "a vida e seus mecanismos entraram no domínio dos cálculos explícitos, e fez do poder-saber um agente de transformação da vida humana”. (Foucault, 2009, p.161). De forma mais específica, Foucault tinha o objetivo de estudar o governo dos homens pela verdade.

Com o objetivo de estudar as relações entre exercício de poder e manifestação de verdade, Foucault realizou no curso de 1979-1980 uma análise minuciosa do cristianismo primitivo, dos modos pelos quais os cristãos são convidados a confessarem a verdade sobre si próprios, principalmente por meio de três práticas: batismo, penitência e direção de consciência. Esses atos representam uma incessante verbalização por meio da qual o cristianismo exige mais que obediência e submissão de seus seguidores; uma vez que cada fiel deve dizer a verdade a propósito de si mesmo, confessando seus pecados e seus desejos mais íntimos. 
Embora Foucault sustente que o poder é agente de produção social, no curso Do governo dos vivos, o autor volta sua atenção a outras formas de saberes e verdades que acompanham o poder. Segundo o filósofo francês, há sempre a manifestação de uma verdade que é irredutível aos saberes produzidos pelo poder, uma verdade que não é da ordem do conhecimento, que atua de forma suplementar, que não tem por objetivo provar algo ou administrar a população, mas desvelar o oculto. A esse fenômeno, Foucault chamou de manifestação de verdade "porque não se trata pura e simplesmente do que poderíamos chamar de uma atividade mais ou menos racional do conhecimento" (Foucault, 2018, p.7). Como exemplo, o autor cita o imperador romano Sétimo Severo, que havia mandado representar no teto da sala de seu palácio a conjunção das estrelas que havia presidido seu nascimento. Sua intenção ao fazer essa manifestação de verdade era clara: mostrar como a posição dos astros no seu nascimento justificava seu poder e suas pronunciações. Desse modo, tratava-se de mostrar como seu reino havia sido fundado de acordo com os astros, como forma de substituir a ordem racional do mundo pela ordem mágica dos astros.

Assim como no exemplo de Sétimo Severo, toda forma de poder vem acompanhada de uma série de atos de verdade como: conhecimento racional, procedimentos verbais ou não verbais; um certo número de informações, como rituais de magia, consulta ao oráculo ou aos deuses. Dessa forma, na aula de 9 de janeiro de 1980, Foucault anuncia um deslocamento teórico:

[...] eu não diria simplesmente que o exercício do poder supõe nos que governam algo como um conhecimento, um conhecimento útil e utilizável. Diria que o exercício do poder se faz acompanhar com bastante constância de uma manifestação de verdade entendida nesse sentido bem lato. (FOUCAULT, 2018, p. 8).

Portanto, trata-se de produzir um deslocamento teórico da noção de podersaber para a noção de verdade, saber racionalizado do governo para os atos de verdade, do saber enquanto produção social para as formas de manifestação de verdade. Para designar essa forma de revelar a verdade oculta, Foucault introduz o conceito de aleturgia para se referir ao:

[...] conjunto de procedimentos possíveis, verbais ou não verbais pelos quais se revela o que é dado como verdadeiro em oposição ao que é falso, ao oculto, ao indizível, ao imprevisível, ao esquecimento, e dizer que não há exercício de poder sem algo como uma aleturgia. (FOUCAULT, 2018, p. 7).

De toda forma, o que vale salientar é que não existe poder independente da manifestação de verdade; pelo contrário, o poder mais forte é aquele capaz de desvelar o maior número de verdades. É verdade que rituais de manifestação de verdade da ordem da magia, como a representação do céu estrelado acima da cabeça do imperador, quase desapareceram, principalmente a partir da perseguição do 
cristianismo e do progresso da racionalidade ocidental a partir do século XV e XVI. A governamentalidade do Estado Moderno veio acompanhada de uma forma racionalizada e calculada de governar, pautada em conhecimentos políticos, econômicos e demográficos. Razão de Estado $^{3}$ remanejou, de forma calculada, as aleturgias que até então acompanhavam o poder dos soberanos. Era preciso eliminar aquele tipo de saber e aquela produção da verdade. Para tanto, os adivinhos e astrólogos foram varridos e substituídos por ministros, instaurando o conhecimento que é a marca de um governo racionalizado.

Foucault havia trabalhado, nos cursos anteriores, a noção biopolítica de governo dos homens enquanto população, governo no sentido mais amplo da palavra, enquanto forma de gerir e dirigir a conduta dos homens. Ao elaborar a noção de governo dos homens pela verdade, o autor promove um deslocamento da noção de poder-saber para a noção de governo pela verdade.

As análises do poder realizadas ao longo dos anos 70 tinham como objetivo formular a relação entre exercício do poder e produção da verdade. "A verdade estava ligada circularmente a sistemas de poder que a produzem e a sustentam, e a efeitos de poder que ela induz e que a trazem de volta”. (Senellart, 2018, p. 312).

A noção poder-saber correspondia à crítica de Foucault ao problema da origem do conhecimento, da busca por uma essência do poder. Dessa forma, com o conceito poder-saber trata de colocar a verdade a nível das relações de poder, o poder enquanto campo de batalha, enquanto algo que não possui uma essência. Quanto a esse tópico, Deleuze interpreta de forma minuciosa a concepção relacional de poder em Foucault:

O poder não tem essência, ele é operatório. Não é um atributo, mas uma relação: a relação de poder é o conjunto das relações de força, que passa tanto pelas forças dominadas quanto pelas dominantes, ambas constituindo singularidades. (DELEUZE, 2005, p. 37).

A crítica foucaultiana ao que Deleuze chama de postulada da essência ou do atributo se prolonga no curso $A$ sociedade punitiva (1972-1973), dessa vez tendo como alvo a abordagem do poder em termos de ideologia. A análise do poder em termos de ideologia repousa na ideia negativa do poder. As relações de poder teriam que ser suspensas para haver uma produção de saber. "Ora, o poder produz realidade antes de reprimir. E também produz realidade, antes de ideologizar, antes de abstrair ou mascarar". (DELEUZE, 2005, p. 38). Sendo assim, "o poder não procede como ideologia, mesmo quando se aplica sobre as almas; ele não opera

\footnotetext{
3 No curso de 1978, Segurança, território e população, Foucault investiga a lógica por trás da política de governo dos homens, uma nova racionalidade que tem como objetivo assegurar a conservação e a defesa do Estado. Dessa forma, Foucault (2008, p.318) define a razão de Estado como "o tipo de racionalidade que vai possibilitar manter e conservar o Estado a partir do momento em que ele é fundado, em seu funcionamento cotidiano, em sua gestão de todos os dias".
} 
necessariamente pela violência e da repressão quando se dirige aos corpos". (Deleuze, 2005, p. 38). Sendo assim, Foucault criou em sua analítica do poder um arcabouço conceitual para conceber o poder de forma relacional.

Os estudos de Foucault dos anos 70 podem ser lidos como uma série de investigações acerca dos mecanismos de poder-saber: investigação do sistema prisional, as ciências humanas, a psiquiatria penal, governo dos homens enquanto população. Dessa forma, o conceito poder-saber foi fundamental na elaboração de uma concepção de poder que contornasse a noção de poder enquanto essência/atribuição ou ideologia/repressão.

No entanto, na aula de 9 de janeiro de 1980, Foucault anuncia querer se livrar do tema poder-saber, "tema já gasto e reprisado". Da mesma forma que esse tema havia permitido ao autor elaborar uma nova concepção de poder, agora ele necessitava de outro conceito para entender a operacionalidade do "governo pela verdade". Os estudos dos regimes de verdade realizados em 1980 não dizem respeito à articulação entre discurso e prática, mas aos procedimentos e aos meios que ligam o sujeito à manifestação da verdade. Senellart deixa claro que o conceito "regime de verdade" foi usado naquele ano para se referir à ideia de que: "é essa relação entre procedimento de manifestações do verdadeiro (ou aleturgia) e formas de implicação do sujeito (operador, testemunha ou objeto) que a palavra regime define" (Senellart, 2018, p. 312).

Feito o deslocamento teórico da noção de poder-saber em direção ao conceito de governo dos homens pela verdade, nas duas aulas seguintes do curso Do governo dos vivos, Foucault revisita Édipo Rei e propõe uma releitura aletúrgica da tragédia de Sófocles, com o objetivo de mostrar a relação entre o governo dos homens e a manifestação do verdadeiro.

\section{3 Édipo rei: dramaturgia da cegueira e a lei das metades}

Foucault não analisa a história de Édipo como sendo a tragédia que instaurou a verdade acerca do inconsciente no Ocidente, mas como uma contra-história, que evidencia a relação entre poder e saber ao expor práticas jurídicas como um dos modos de desvelar a verdade. $\mathrm{O}$ autor francês chega a afirmar que, além do direito, a trama é permeada por uma metáfora médica. A luta para curar Tebas da peste indica que "no limite Édipo é uma questão de medicina e de direito". (Foucault, 2018, p.54).

$\mathrm{Na}$ história que perpassa o direito da Grécia Antiga, Foucault encontrou elementos para investigar a origem das práticas jurídicas, em especial o inquérito, além de outras práticas fundamentais como o testemunho e a confissão. Essa análise foucaultiana realizada nos anos 70, principalmente em $A$ verdade $e$ as formas jurídicas, é a mais estudada, porém a releitura feita em Do governo dos vivos traz a tona elementos da fase ética de Foucault que ainda permanecem pouco explorados e 
que merecem maior atenção pelo seu conteúdo e pelo modo como o autor usa o ficcional para explicar elementos políticos e históricos.

No início de sua abordagem na aula de 16 de janeiro de 1980, Foucault começa por analisar de forma minuciosa a dramaturgia grega. Para o autor, toda tragédia é uma forma de dizer a verdade: os heróis, os mitos e os atores trazem à tona uma verdade que até então era desconhecida ou permanecia em segredo durante todo o enredo. O motor da história de Sófocles é a busca pelo assassino do rei.

No interior da tragédia grega há uma economia própria, um modo de fazer aparecer à verdade. Para fundamentar sua análise das tragédias, Foucault cita $A$ Poética, de Aristóteles, texto no qual o autor grego afirma haver alguns elementos constitutivos da tragédia, como a peripécia e o reconhecimento. A peripécia é o movimento pelo qual a fortuna dos personagens se inverte: os miseráveis se revelam fortes e poderosos, detentores da verdade e do poder. Esses movimentos estão muito presentes na peça de Sófocles. Édipo foi abandonado pelos pais, mas chega ao trono de Tebas. No final da peça, perde seu poder. O reconhecimento, por sua vez, é definido por Aristóteles como:

[...] a passagem da ignorância para o conhecimento, para a amizade ou para o ódio entre aqueles que estão destinados à felicidade ou à infelicidade. $\mathrm{O}$ reconhecimento mais belo é aquele que se opera juntamente com peripécia, como acontece no Édipo. (ARISTÓTELES, 2008, p. 56).

Reconhecimento seria o momento da descoberta da verdade. No final da peça, o assassino de Laio é revelado. A profecia se cumpriu: Édipo matou o pai e deitou-se com a mãe. Porém, em Édipo rei, o reconhecimento tem uma forma peculiar: o personagem procura por uma verdade da qual ele é o próprio objeto. Dessa forma, o personagem submete-se a solucionar um crime do qual ele mesmo é o culpado.

Em Do governo dos vivos, Foucault volta a se referir à história de Édipo como uma dramaturgia da cegueira. O trágico destino do herói de Sófocles é definido pela força do olhar. É pela visão que a verdade se manifesta. Dessa forma, a história é uma dramaturgia da cegueira, "uma dramaturgia das verdades múltiplas, das verdades profusas, das verdades a mais" (Foucault, 2018, p.25).

No último ato, Édipo, que exigia ver a verdade com seus próprios olhos, acaba por tornar-se cego. Em um momento de desespero, o herói de Sófocles tira sua própria visão, escondendo-se assim na escuridão. Impossibilitado de captar o esplendor divino, os olhos mortais têm acesso agora "a uma outra luz, a luz ofuscante e terrível do divino" (VERNANT e PIERRE, 1999, p. 80). Mas Foucault aponta para o fato de que Édipo vê com seus olhos humanos, nas cenas finais, a revelação da verdade: Édipo é o filho abandonado de Laio, criado por Políbo, o que trouxe a desgraça para Tebas. 
Um conjunto de expressões faz referência à visão como elemento fundamental

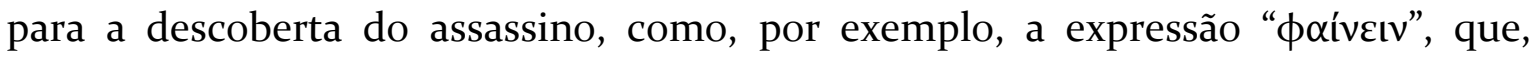
significando "trazer à luz, tornar visível", termo que possuía na época uma função jurídica, referindo-se "naturalmente, a um termo associado ao processo legal (trazer um criminoso, ou um crime, à luz, informando às autoridades), e esse significado opera plenamente na peça” (KNOX, 2002b, p. 115).

Até que o assassinato de Laio, que pertence à ordem das coisas obscuras, seja

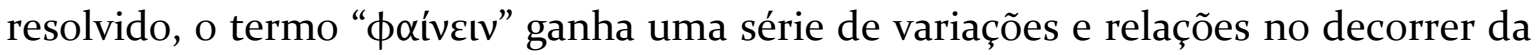
trama. O termo é relacionado, por exemplo, com a expressão “ $\sigma \alpha \phi \eta ́ \varsigma$ ” que no século $\mathrm{V}$ designava algo como verdadeiro.

Abrir os olhos, encontrar a verdade, eis a grande vontade de Édipo que está no centro da trama. "Édipo é o homem que não cessa de dizer: 'eu inquiri, e como ninguém foi capaz de me dar informações, abri os olhos e os ouvidos, eu vi”. (FOUCAULT, 2018, p. 25). Ao “abrir os olhos", Édipo então torna-se vítima da busca que ele próprio promoveu.

Na história de Édipo, a verdade é descoberta pouco a pouco, como peças que vão se encaixando em um quebra-cabeças, o que o filósofo francês chamou de lei das metades. Duas metades formam o quebra-cabeça: a metade dos deuses, representada pelo deus e pelo profeta; a metade humana, uma referente ao assassinato, proferida por Jocasta, Édipo, pelo mensageiro e pelo escravo.

A propósito de descobrir o assassino, Édipo propõe interrogar a população, proposta que logo é rejeitada pelo coro, pois seria uma forma de desconfiar dos tebanos. Sendo assim, só resta a Édipo uma segunda alternativa, que é consultar o profeta, o adivinho Tirésias. O profeta não quer dizer o que sabe, mas é pressionado por Édipo e acaba por revelar "Afirmo QUE ÉS TU o assassino que procuras". (SÓFOCLES, 1980, p. 30). Dessa forma, Tirésias revelara a outra metade do enigma, a metade do assassino, que não havia sido revelada pelo oráculo. Nesse momento, a aleturgia dos deuses está completa, e toda verdade sobre o assassinato é revelada.

Apesar da revelação, a acusação de Tirésias não foi suficiente para provar a culpa de Édipo, que tinha um governo sólido e era respeitado em Tebas. Durante o confronto entre Édipo e Tirésias, o Corifeu diz "as acusações de Tirésias valem tanto quanto as de Édipo. Os dois falam sob o efeito da cólera”. O coro também se recusa a tomar partido. Foucault aponta novamente para a importância da visão como um dos eixos da peça: o coro e Corifeu necessitavam de provas, precisavam ver com os próprios olhos a concretização da acusação feita pelo profeta. "Édipo tem para si coisas visíveis e são elas que impedem o coro de dar o crédito necessário e suficiente às palavras divinas" (Foucault, 2018, p.28). 
Depois da metade divina, a segunda metade da verdade sobre a morte de Laio é a metade humana. Esta se divide em duas partes: a descoberta do assassinato e a descoberta do nascimento.

Feita a acusação contra Édipo, Jocasta tenta ajudar o marido dizendo "tranquilize-se, não foste tu que podes ter matado Laio, pois ele foi morto em uma encruzilhada por bandidos" (SÓFOCLES, 1980, p. 42). A verdade dita por Jocasta é a história que os tebanos conhecem a respeito da morte do velho rei. A outra metade sobre o assassinato pertence a Édipo, a metade da qual os tebanos estão privados. Resta, então, a ele ordenar seus pensamentos e dizer que também matou um homem em uma encruzilhada.

Antes de chegar o escravo, única testemunha da morte do rei, surge no palco um mensageiro de Corinto que anuncia a Édipo a morte de Políbio, e que este não era seu pai. Começa a ser descoberta a verdade sobre o nascimento de Édipo. Nesse momento surge o escravo que testemunhou o crime, e que também é a pessoa a quem foi confiado Édipo depois que seus pais quiseram matá-lo. O escravo é a última peça do quebra-cabeças: "Diziam que era filho dele próprio (Laio)". (SÓFOCLES, 1980, p. 58). O inquérito, enfim, é concluído.

O autor sustenta que, na peça, a aleturgia possui dois vetores se consumando duas vezes: a aleturgia dos deuses e a dos escravos. Sendo assim, Édipo e Jocasta seriam figuras intermediárias nesse processo. "São duas as formas de aleturgia que juntas constituem a boa palavra, a palavra reta que é, no final das contas, a portadora da verdade" (FOUCAULT, 2018, p. 45). Dessa forma, destacaremos no próximo tópico as diferenças entre essas duas formas de aleturgia, e em quais as implicações dessa revelação no governo de Édipo.

\section{Dramaturgia da temporalidade}

Foucault constata, na aula de 16 de janeiro, que o desencadeamento dos fatos em relação à morte do velho rei acontece paulatinamente, o que seria então uma segunda forma de dramaturgia, uma dramaturgia da temporalidade. Três grupos diferentes detêm, cada qual, um fragmento da verdade. Primeiro, no nível dos deuses, o oráculo e Tirésias. Segundo, no nível humano, Jocasta e Édipo em uma discussão que se situa entre as duas formas de aleturgia. Por fim, a verdade dos escravos, que reforçam o que foi dito pelos deuses e acrescentam a verdade sobre $o$ nascimento de Édipo. São três grupos, seis fragmentos que vão se encaixando e que juntos revelam a verdade.

Entre esses personagens, em cada um dos grupos acima, há um vínculo. No primeiro grupo, formado pelo deus e pelo profeta, o vínculo é de ordem religiosa, pois o profeta recebeu de um deus o dom de dizer a verdade. Em segundo lugar, entre Édipo e Jocasta existe o vínculo mais delicado. Isso porque, além de ser mulher 
de Édipo, Jocasta também é aquela que o concebeu. E nisso reside a maldição e, consequentemente, a desgraça que caiu sobre Tebas. E, enfim, entre os dois servos, o mensageiro e o escravo, há um vínculo de amizade. Assim, existem, entre os personagens, vínculos de naturezas diferentes, que podem ser analisados de forma hierárquica: pacto de amizade, pacto jurídico e pacto religioso.

Além da análise do vínculo entre os personagens, Foucault chama atenção para o fato de que Édipo é, ao mesmo tempo, um ser de duas naturezas e um ser duplo. Édipo, que até então era um ser fragmentado, nascido em Tebas e crescido em Corinto, verá a si, no fim da peça, como um ser de monstruosa dualidade: ele é filho e esposo de sua mãe, pai e irmão de seus filhos.

A comparação entre as duas formas de aleturgias encontradas na peça está no centro da análise de Foucault. Entre a aleturgia divina e a aleturgia dos escravos há três diferenças: na forma de extração da verdade, na composição do saber e na temporalidade em que se situam ambos os discursos.

Tanto os deuses quanto os escravos são sujeitos interrogados, detentores da verdade. A diferença está na forma como se dá esse interrogatório. Os deuses são consultados, e depois de dada a resposta não são mais. Por ser uma entidade superior, por mais incompleta que seja a resposta desse deus, não se pode contestála. "O jogo de pergunta resposta com o deus é um jogo que se joga uma vez por todas, e, terminada a partida, há que se conformar com o resultado” (FOUCAULT, 2018, p. 33).

Apesar de ter recebido de um deus a capacidade de dizer a verdade, o profeta Tirésias é consultado de modo diferente. Mesmo encarregado de proteger a cidade, Tirésias recusa a verdade por vontade própria, foi obrigado por Édipo. Diferente do deus, Tirésias é ameaçado de morte e interrogado em pé de igualdade, de rei para rei.

A terceira consulta procede do mensageiro e do escravo e vai acontecer de forma diferente da feita ao deus e ao profeta Tirésias. O primeiro a ser interrogado é o mensageiro que traz a notícia da morte de Políbio. O pastor, último a ser interrogado, é detentor de toda a verdade. Isso porque ele salvou Édipo de ser morto por seus pais e assistiu à morte de Laio. Dessa forma, o pastor sabe de toda a verdade e possui um saber que equivale a de um deus que tudo vê. Mesmo sabendo de tudo, ele não é interrogado em pé de igualdade, como Tirésias. Pelo contrário, hesitando em dizer o que sabe, é ameaçado de morte por Édipo.

A segunda diferença está na composição do saber dos deuses e dos escravos. "O saber dos deuses, no entanto, assim como dos escravos, é uma certa maneira de compor o olhar e o discurso, ou ainda de compor o ver e o dizer" (FOUCAULT, 2018, p. 35). O deus vê tudo, ilumina todas as coisas e as torna visíveis. É a luz dos olhos dos deuses que iluminam o mundo. A luz dos deuses não só iluminam as coisas 
como as determinam. Dessa forma, não tem como os deuses não dizerem a verdade, pois "há uma conaturalidade entre a luz que habita o olhar do deus e a visibilidade das coisas, ela diz as coisas e faz as coisas acontecerem". (FOUCAULT, 2018, p. 35)

Nos escravos, o saber e o dizer são compostos de outra maneira. Os escravos assistem passivamente aos acontecimentos. Eles apenas obedecem, exceto quando o pastor salvou Édipo da morte. O que assegura a verdade de seu testemunho é o fato de estarem presentes, vendo com seus próprios olhos.

\footnotetext{
Eles estão na verdade, não sendo habitado por elas. Eles é que habitam a verdade ou que, pelo menos, visitaram uma realidade, fatos, ações, personagens, sobre as quais, em nome de sua identidade, em nome do fato de que são eles mesmos e que são sempre os mesmos, nessas condições eles podem ter um discurso. (FOUCAULT, 2018, p. 37).
}

A terceira diferença entre a aleturgia dos deuses e a aleturgia dos escravos diz respeito ao tempo em que o personagem situa seu discurso. $\mathrm{O}$ deus e o adivinho, como habitantes da verdade, situam seu discurso no eixo do presente e do futuro, sempre fazendo uma relação entre os dois. A manifestação dos escravos se situa no passado, pois mensageiro e o pastor relatam coisas que já aconteceram. E a parte da verdade que não havia sido revelada pelos deuses é, enfim, validada e completada pelos escravos. O deus anuncia e pronuncia, enquanto o escravo reconhece e confessa.

\section{O saber de Édipo: relação entre governo e aleturgia}

Foucault constata que as duas formas de aleturgia destacadas anteriormente giram em torno da primeira pessoa, passam pelo íntimo de quem manifesta a verdade. Os atos de verdade são validados pela afirmação da identidade da testemunha, por isso a necessidade de dizer "eu", "eu mesmo".

Essa identificação do dizer-a-verdade e do ter-visto-a-verdade, essa identificação entre aquele que fala e a fonte, a origem, a raiz da verdade, e aí sem dúvida um processo múltiplo e complexo que foi capital para a história da verdade em nossas sociedades". (FOUCAULT, 2018, p. 47).

Édipo, situado entre essas duas formas de aleturgias, é marcado por um não saber, por uma ignorância. Quando o personagem pratica o que Foucault chama de autoaleturgia, quando o herói de Sófocles diz "eu sei", sabemos que o que ele acredita saber não é a verdade dos fatos, ou é, pelo menos, uma parte dela. Todas essas expressões que marcam o saber dos outros personagens, no caso de Édipo, remetem à sua ignorância.

Édipo é o homem que não sabe, e a peça gira em torno do reconhecimento, de modo que Édipo passa do homem que não sabia para o que sabe. Ele mesmo quer fazer essa descoberta, pois não confia em mais ninguém, ou seja, o próprio Édipo é o operador dessa verdade. Mesmo fazendo da descoberta sua propriedade, ao longo 
da peça não é à verdade que Édipo faz referência, mas ao poder. Para o personagem, não se trata de um jogo de verdade, mas de um jogo de poder. Na discussão com Tirésias, Édipo não se defende dizendo que não matou o rei ou que ainda não era um tebano quando ocorreu o assasinato. Ao contrário, ele diz "ó riqueza! Ó poder! Ó glória de uma vida consagrada a ciência, quanta inveja despertais contra o homem a quem todo mundo admira" (SÓFOCLES, 1980, p. 31). Assim como nessa passagem, ao longo da peça, Édipo só enxerga o poder.

Entre a aleturgia dos deuses e dos escravos, há o canto do coro, que consiste em um elogio às leis e uma crítica aos tiranos, que, claramente, refere-se a Édipo. Foucault situa a figura do tirano no contexto histórico em que a peça se passa, no qual o termo tirania não tinha um sentido pejorativo como atualmente:

\begin{abstract}
A tirania foi um modelo constante e ambíguo para o pensamento político na Grécia, e por várias razões. E, no final das contas, poderíamos dizer que a tirania foi para o pensamento político grego o que foi a revolução para o pensamento europeu moderno, aquilo em relação a que, no fim das contas, sempre é preciso se situar e que deve ser pensado ao mesmo tempo como passagem, transição, fundação ou subversão (FOUCAULT, 2018, p. 59).
\end{abstract}

Essa figura ambígua do tirano, que é positiva e negativa, pode ser encontrada na forma de governar de Édipo. Algumas das características que marcaram o herói tirano das tragédias gregas estão presentes na obra de Sófocles. Édipo teve um destino desigual, marcado por inconstâncias. O personagem passou por altos e baixos, que se alternaram por toda sua trajetória. Em segundo lugar, o fato de Édipo ter salvado a cidade autentica seu poder, ainda que ele não seja nobre de berço. Ao salvar Tebas, Édipo se vinculou a ela, tornando-se uma espécie de proprietário. Sua ação baseia-se, então, não em um poder recebido por herança, mas em sua vontade de conduzir os homens na descoberta dos melhores meios de proteger seus súditos e validar seu poder. Sendo obrigado a descobrir enquanto governa, Édipo situa seu poder em um jogo de verdades no qual ele mesmo se torna vítima.

Foucault termina sua análise concluindo que a peça não critica a busca pela verdade nem as formas de aleturgia identificadas pelo autor, mas sim a pretensão de Édipo em querer ser o mestre dessas aleturgias, e sua intenção em usar dessa verdade para proveito próprio.

\title{
Considerações finais
}

O artigo se propôs, seguindo a leitura de Foucault e outros comentadores, a analisar Édipo Rei como uma obra constituída por duas dramaturgias: da cegueira e da temporalidade. A complexidade dos personagens e a multiplicidade de acontecimentos presentes na tragédia de Édipo servem de base para interpretar a dramaturgia e a sociedade grega antiga, bem como elementos fundamentais da nossa sociedade. Para Foucault, Édipo é mais do que a história do inconsciente, é 
uma história sobre poder e saber, do nascimento de novos procedimentos jurídicos estabelecidos na tragédia por Édipo.

Na leitura realizada em 1980, Foucault utiliza-se da obra de Sófocles para explicitar a relação entre manifestação da verdade e exercício do poder. A revelação da verdade era a condição necessária para o reestabelecimento do equilíbrio em Tebas, e consequentemente, para a continuação do exercício do poder. Mesmo tendo sido revelada pelos deuses, houve a necessidade de uma confirmação dessa verdade, uma necessidade de autoaleturgia. Assim como nos procedimentos do cristianismo, sem essa subjetivação, sem essa passagem da verdade pela primeira pessoa, pelo "eu" que testemunhou os fatos, a verdade permaneceria inacabada. É nesse processo de subjetivação que reside, segundo o autor, um ponto fundamental da história da verdade.

Foucault usa da peça para exemplificar que, assim como na cultura ocidental cristã, o sujeito na trama de Sófocles tem um duplo papel: ator nas relações de poder e também nos atos de verdade, dos quais o sujeito é ao mesmo tempo ator, testemunha e objeto. Ao proferir a verdade, o escravo torna-se ator da aleturgia ao narrar os fatos do qual foi ao mesmo tempo testemunha e objeto. No centro da aleturgia revelada pelos deuses e pelos escravos encontra-se Édipo, o reflexo da figura do tirano do século $\mathrm{V}$, que ao tentar ser o operador da verdade, tornou-se vítima de sua própria descoberta e não se cegou por culpa, mas por excesso de informação.

\section{Referências}

ARISTÓTELES. Poética. São Paulo: Abril Cultural, 1973.

DELEUZE, G. Foucault. 5. ed. São Paulo: Brasiliense, 2005.

DREYFUS, H. L.; RABINOW, P. Michel Foucault: uma trajetória filosófica. Para além do estruturalismo e da hermenêutica. Rio de Janeiro: Forense Universitária, 1995.

FOUCAULT, M. História da sexualidade: a vontade de saber. 19. ed. São Paulo: Graal, 2009. . A verdade e as formas jurídicas. Rio de Janeiro: Nau, 2002.

. Do governo dos vivos. São Paulo: Martins Fontes, 2018.

. Vigiar e punir: nascimento da prisão. Petrópolis, RJ: Vozes, 2014.

KNOX, Bernard. Édipo em Tebas. São Paulo: Perspectiva, 2002b.

SENELLART, M. "Situação do curso". In: FOUCAULT, M. Do governo dos vivos. São Paulo: Martins Fontes, 2018.

SÓFOCLES. Ésquilo. Rei, Édipo, Antigone; Prometeu Arrependido: tragédias gregas. Rio de Janeiro: Ediouro, 1980.

VERNANT, Jean-Pierre; VIDAL-NAQUET, Pierre. Mito e tragédia na Grécia Antiga. São Paulo: Perspectiva, 1999 
Exercício do poder e manifestações da verdade na análise foucaultiana do Édipo Rei

Submissão: 30. 03. 2020 / Aceite: 14. 08. 2020 